\title{
Da Concessão Reid ao Fim de São João Marcos (1899-1945)
}

\author{
Eduardo Oliveira Estiliano ${ }^{1,2}$, Francisco Gerson Araújo ${ }^{1}$ \\ ${ }^{1}$ Laboratório de Ecologia de Peixes, Universidade Federal Rural do Rio de Janeiro - UFRRJ
}

${ }^{2}$ Programa de Pós-graduação em Ciências Ambientais e Florestais, Universidade Federal Rural do Rio de Janeiro - UFRRJ

\begin{abstract}
RESUMO
Com a construção do reservatório de Lajes, a Rio Light, hoje LIGHT S.A., deu início à construção de um Complexo Hidrelétrico para atender à crescente demanda da região metropolitana do Rio de Janeiro por energia elétrica. Embora extremamente impactante, essa primeira obra do Complexo de Lajes foi um marco e um grande avanço para a época (início do séc. XX), pois, afinal de contas, construiu-se um reservatório com um espelho d'água de $30 \mathrm{~km}^{2}$ para a geração de energia elétrica por força hidráulica. Este trabalho busca apresentar de forma concisa um pouco dessa história marcada por conflitos de interesses políticos, longas disputas judiciais e pela destruição da cidade de São João Marcos-RJ.
\end{abstract}

Palavras-chave: reservatório de Lajes, São João Marcos, complexo hidrelétrico de Lajes.

\section{From Concession Reid to the End of the Municipality of Sao Joao Marcos (1899 - 1945)}

\begin{abstract}
With the construction of the 'Lajes' reservoir, 'Rio Light' power company, nowadays 'LIGHT S.A.', began the construction of a hydroelectric power plant complex to supply the increasing demand for electric energy of the metropolitan area of Rio de Janeiro. Although causing heavy environmental damages, the first part of the 'Lajes' complex was a turning point and a great advancement at the time (the beginning of the twentieth century) when a $30 \mathrm{~km}^{2}$ surface water reservoir was built for hydroelectric power generation. This study aims to record a little of this history by presenting government policy conflicts, law disputes and the destruction of the whole municipality of Sao Joao Marcos-RJ.
\end{abstract}

Keywords: Lajes reservoir, São João Marcos, Lajes hydroelectric complex. 


\section{INTRODUÇÃO}

A história da criação do reservatório de Lajes se confunde com as histórias da eletrificação e do abastecimento público de água da cidade do Rio de Janeiro, do fim do município de São João Marcos, bem como com a história da própria empresa Rio Light, hoje LIGHT S.A.

Segundo Weid (2008), apesar de ser a Capital do Império do Brasil, a cidade do Rio de Janeiro até meados do século XIX era ainda uma cidade com aspecto colonial: ruelas estreitas e casas mal construídas, o centro superpovoado e insalubre. Em meio às dificuldades do traçado urbano, foram estabelecidos serviços públicos que procuravam resolver os problemas mais urgentes, como a iluminação a gás (1854), a instalação de uma rede de esgotos (1864) e os transportes coletivos sobre trilhos.

Entretanto, a partir do final do ano de 1880, o seu crescimento foi exponencial. Nessa mesma época, já em regime republicano, a cidade foi elevada a capital federal e a crescente demanda por novas fontes de energia elétrica levaram a prefeitura a instituir a primeira concessão municipal para o fornecimento de energia elétrica para o Distrito Federal, a concessão Reid. Deste ponto em diante, começa a história da criação do reservatório de Lajes, marcada por grandes impactos ambientais e socioeconômicos e uma intensa disputa pela implantação dos serviços de energia elétrica na cidade do Rio de Janeiro travada entre a Rio Light e a Guinle \& Cia.

\section{A ELETRIFICAÇÃO DA CIDADE DO RIO DE JANEIRO}

A primeira experiência de iluminação utilizando energia elétrica no País foi realizada em 1857, no Rio de Janeiro, com um baile em homenagem a D. Pedro II. Em 1879, a iluminação elétrica permanente chega à cidade, com a instalação de quatro lampiões na plataforma da estação central da Estrada de Ferro D. Pedro II e dois no salão de entrada. Durante a década de 1880, intensificaram-se os experimentos pontuais com eletricidade, utilizando processos diversos de produção de energia. Em 1884, foi renovada a iluminação do Paço Imperial, passando o sistema a ser alimentado por uma pequena termelétrica. No ano seguinte, foi a vez da Biblioteca Real ser iluminada com energia elétrica produzida por uma pequena usina a vapor (Weid, 2008a).

O recém-instalado regime republicano, por meio da constituição de 1891, transformou o antigo Município Neutro no Distrito Federal. Como capital federal, a cidade passou a ser administrada simultaneamente pelos governos central e municipal. Coube ao Congresso Nacional legislar, com exclusividade, sobre a organização do Distrito Federal e os serviços de polícia, ensino superior, entre outros serviços que fossem atribuídos à União. E essas disposições foram reguladas pela Lei Orgânica do Distrito Federal, de Setembro de 1892. Já em relação ao fornecimento de energia elétrica, a municipalidade atuou com plenos poderes, configurando dualidade de competências no que concerne aos serviços públicos de eletricidade do Distrito Federal, refletida na legislação e nos atos administrativos emanados de decisões, quer municipais quer federais (Lamarão, 2002; Weid, 2008b).

O serviço de iluminação era explorado inicialmente pela empresa belga Société Anonyme du Gaz (SAG), que detinha não só o privilégio do fornecimento dos serviços de iluminação pública e particular, como também era a única empresa autorizada a assentar tubulações nas ruas. Então, todo e qualquer empresário que pretendesse implantar uma rede de distribuição de eletricidade (seja aérea ou subterrânea) ficava nas mãos da Société (Hansen, 2008; Lamarão, 2002).

Em dezembro de 1899, na gestão do prefeito Cesário Alvim, o Conselho Municipal institui a concessão Reid através de um decreto municipal, sendo essa a primeira concessão municipal referente ao fornecimento de energia elétrica ao Distrito Federal, que atribuía a Willian Reid \& Cia o direito de instalação de usinas distribuidoras de energia elétrica gerada por força hidráulica. Reid havia descoberto um local propício para a exploração hidrelétrica no ribeirão das Lajes, localizado no município de Piraí, nos contrafortes da serra das Araras. Esse local era chamado Salto do Ribeirão das Lajes devido à existência de uma grande cachoeira 
nas escarpas da serra (Hansen, 2008; Cabral, 2006; Lamarão, 2002).

Em junho de 1900, Cesário Alvim concedeu a William Reid \& Cia o direito de gerar e distribuir eletricidade de origem hidráulica ao Distrito Federal - com exclusividade até 1915 e sem exclusividade até 1950 -, para todos os fins, exceto o de iluminação, preservando assim os direitos da SAG. Todavia, Reid pouco fez para instalar o seu sistema hidrelétrico, limitando-se a limpar o terreno em ribeirão das Lajes e a dar início aos estudos de engenharia (Lamarão, 2002).

Em maio de 1904, os canadenses Frederick Pearson e Alexander Mackenzie, associados ao capitalista norte-americano Percival Farquhar, constituíram a Rio Light, mais tarde The Rio de Janeiro Tramway Light and Power, que, através de Mackenzie, em janeiro de 1905, adquiriu a concessão Reid e, no mesmo ano, absorveu todo o capital da SAG. Em maio, a Rio Light foi autorizada a funcionar no Brasil e, em dezembro, iniciou a construção da hidrelétrica de Fontes, no ribeirão das Lajes (Cabral, 2006; Lamarão, 2002; Kessel, 2001; Rocha, 1997; Paula, 1996).

No entanto, sua entrada no mercado de eletricidade do Distrito Federal foi marcada por uma oposição violenta por parte do grupo GraffréeGuinle. Entre 1905 e 1915, a empresa canadense e o grupo de capital nacional, depois Guinle \& Cia., e mais tarde Companhia Brasileira de Energia Elétrica (CBEE), travaram uma disputa acirrada pela primazia do fornecimento de energia elétrica ao mercado carioca: os Guinle também investiam, entre outros, na construção da sua primeira usina geradora de eletricidade por força hidráulica (hidrelétrica de Piabanha, no rio Piabanha, em Alberto Torres, no município de Paraíba do Sul) e negociavam com a Societé Travaux et D’Entrepreses ao Brésil para fornecer energia elétrica para Niterói e outras localidades do Estado do Rio (Hansen, 2008; Lamarão, 2002; Kessel, 2001).

O conflito ultrapassou a arena da iniciativa privada, colocando em campos antagônicos a prefeitura do Distrito Federal e o governo federal. Os enfrentamentos entre as duas empresas, suas estratégias empresariais embasadas em pareceres de juristas de renome, as redes de apoio por elas tecidas no aparelho de Estado e nos meios de comunicação, as discordâncias entre os governos federal e municipal no que tange à geração e ao fornecimento de energia elétrica postergaram a instalação e a ampliação dos serviços de eletricidade na capital federal (Kessel, 2001).

\section{A CONSTRUÇÃO DO RESERVATÓRIO}

Numa primeira etapa, foi construída uma casa de força provisória no ribeirão das Lajes que, inaugurada em janeiro de 1907, passou a atender às obras da usina permanente de Fontes. Ainda em 1907, foi iniciada a construção da subestação transformadora da rua Frei Caneca, no centro do Rio. A hidrelétrica de Fontes foi inaugurada no começo de 1908 (Weid, 2008a). Em abril, com $12.000 \mathrm{~kW}$ de potência instalada, a usina era a maior do Brasil e uma das maiores do mundo.

Em fevereiro de 1907, a Guinle \& Cia. logrou a publicação de um decreto federal que a autorizava a participar da concorrência para o fornecimento de energia elétrica aos serviços públicos federais instalados na cidade do Rio de Janeiro, através da energia a ser produzida pela hidrelétrica de Piabanha. Contudo, as iniciativas dos Guinle esbarraram nas resistências da prefeitura carioca (Hansen, 2008; Lamarão, 2002).

\section{A CONSTRUÇÃO DO RESERVATÓRIO DE TÓCOS}

A Rio Light obteve do governo fluminense o direito de utilizar parte das águas do rio Piraí com a finalidade de aumentar a capacidade de produção de energia elétrica na usina de Fontes em construção, uma vez que a hidrelétrica não comportava outras alternativas de ampliação. Depois que dois geradores adicionais foram instalados em 1909, aumentando sua capacidade para $24.000 \mathrm{~kW}$, o único caminho para assegurar mais energia era desviar as águas do Piraí, através de um túnel, empreendimento sofisticado e caro. Mas os Guinle conseguiram sustar as obras através de ação judicial (Lamarão, 2002).

O início das obras foi adiado até novembro de 1911, o grande túnel foi aberto e por ele passam hoje as águas do rio Piraí, para caírem no leito do 
Rosário, que, por sua vez deságua no rio Araras. Esse túnel tem uma extensão de $8.429 \mathrm{~m}$, traçado em linha reta e aberto em rocha granítica, que foi perfurada por meio de brocas e todo o mecanismo movido por motores elétricos (Dantas, 1931). Com esse desvio, o reservatório de Lajes passou a ter uma afluência total média de $18,5 \mathrm{~m}^{3} / \mathrm{s}$, sendo $5,7 \mathrm{~m}^{3} / \mathrm{s}$ de sua própria bacia e $12,8 \mathrm{~m}^{3} / \mathrm{s}$ oriundos de Tócos: possuindo um espelho d'água de $30 \mathrm{~km}^{2}$ e sendo o maior lago artificial do Estado do Rio de Janeiro, com uma capacidade de armazenamento de 452 bilhões de litros, com tempo de residência em torno de 282 dias. A superfície do espelho d'água registra comprimento e largura máximos de $20 \mathrm{e}$ $5 \mathrm{~km}$ respectivamente, e profundidade média de $15 \mathrm{~m}$ e valores máximos próximos de $40 \mathrm{~m}$ (Light/ Iesa, 1991). Hoje o reservatório além da geração de energia ainda fornece água para os bairros da Tijuca, Lapa e Centro do município do Rio de Janeiro (Lamarão, 2002).

Se por um lado as obras trariam inúmeros benefícios, pois além da produção de energia o reservatório de Lajes atenderia à demanda crescente de água do Distrito Federal, por outro lado, junto com elas viriam inúmeros impactos tanto ambientais quanto socioeconômicos.

\section{SÃO JOÃO MARCOS: 200 ANOS DE HISTÓRIA INUNDADOS OU SIMPLESMENTE DEMOLIDOS}

A fundação de São João Marcos tem origem no processo de expansão territorial do século XVIII, através da busca de novos caminhos terrestres que ligassem as capitanias de São Paulo e Minas Gerais com o Rio de Janeiro (Paula, 1996). Por volta de 1730, o Governador e Capitão-Geral da Capitania do Rio de Janeiro, Luiz Vahia Monteiro, mandou abrir novos caminhos para a Capitania de São Paulo, para que se evitasse o extravio de ouro e os desentendimentos com os índios que habitavam as regiões de São João Marcos, Piraí, e Campo Alegre em Rezende. Esta decisão foi tomada de conformidade com carta de Dona Maria I, Imperatriz do Brasil, ao Ouvidor Marcelino Pereira Cleto. Abrindo-se estradas para esses lugares, para ali correram os primeiros povoadores. Em 1737, João Machado Pereira fundava em sua fazenda a Freguesia, tendo como padroeiro São João Marcos. Logo em seguida, afazendou-se na região sertaneja Antônio de Souza Breves e sua mulher, dedicando-se ao desbravamento das matas, cultivando e formando fazenda, para o que obtivera sesmarias de largas terras (Taunay, 1932; apud Beiler, 2001).

A capela dedicada a São João Marcos foi tida por paróquia desde o ano de 1739 , e as terras adjacentes que se achavam povoadas se intitularam do nome do referido santo. $\mathrm{O}$ tempo foi passando e a população crescendo de uma tal forma que o príncipe regente a elevara a dignidade de vila, cujo título lhe conferiu dando-lhe o nome de São João do Príncipe (Bopp, 1973).

O município era constituído pelas paróquias de São João Marcos e Nossa Senhora da Conceição do Passa Três. O município tornou-se grande produtor de café no século XIX, com a expansão do cultivo desse produto no Vale do Paraíba (Paula, 1996). São João Marcos era um dos principais núcleos produtivos (cerca de 2 milhões de arrobas de café por ano) e estava numa posição geográfica privilegiada: no centro da área produtora, na confluência de grandes rios, próximo à capital (Corte) e com ligação direta com o mar via Mangaratiba (Beiler, 2001).

São João Marcos viveu intensamente o brilho da era dos barões do café, no século XIX: foi uma das mais importantes cidades, com 20.000 habitantes, teatros, escolas públicas e fábricas. Também foi em São João Marcos que construíram a primeira estrada de rodagem do Brasil, em 1856, com $40 \mathrm{~km}$ de extensão, para escoar o café das fazendas do Vale do Paraíba para o Porto de Mangaratiba. Como berço da expansão cafeeira no Vale do Paraíba, São João Marcos abrigou em suas terras os mais poderosos e abastados fazendeiros do País, entre eles o Comendador Joaquim José Breves, considerado "o rei do café" no Brasil Imperial, e suas plantações abasteceram o mercado europeu do século XIX (Araújo, 2008; Beiler, 2001).

Em sua jornada histórica pelo vale do Paraíba em agosto de 1822, Dom Pedro I, em seu segundo dia de viajem, se hospedou em São João Marcos, na Fazenda Santo Antônio da Olaria, de propriedade do capitão Hilário Gomes Nogueira. No dia seguinte, seguiu percorrendo extensas áreas por terras dos Breves, na 
companhia do jovem Joaquim Breves (Araújo, 2008; Beiler, 2001; Pasin, 1973).

Da época do café, a cidade herdou a arquitetura colonial, estampada em seus casarios e igrejas. Passado o boom cafeeiro, a região entrou em processo de decadência econômica, sobrevivendo através de pequenas produções para consumo interno e para exportação regional, além da pecuária extensiva (Paula, 1996). São João Marcos foi perdendo importância e sua população ficou reduzida a pouco mais de 7 mil pessoas no início do século XX.

Quando no ano de 1905, a Light iniciou suas obras da usina de fontes em Piraí - RJ, a parte mais baixa da cidade e as maiores propriedades da área rural de São João Marcos seriam inundadas (Araújo, 2008; Beiler, 2001). Dentre elas a fazenda da Olaria, a qual acolheu Dom Pedro, e cujo solar fora substituído por um novo palácio quando essa propriedade fora adquirida pelo comendador Joaquim Breves. O novo solar fora construído em 1865 por um arquiteto vindo da Itália, e era uma reprodução fiel do palácio de Podestá, na Bréscia; seus assoalhos eram em mosaicos e o piso do saguão de entrada era feito em mármore de Carrara (Araújo, 2008; Beiler, 2001).

A inundação teve início: os morros logo se transformaram em ilhas e uma centena de fazendas coloniais foi tragada. Os luxuosos teatros, bibliotecas e capelas desapareceram da noite para o dia. Plantações e casas sumiram sob as águas turvas do ribeirão das Lajes e seus afluentes (Beiler, 2001; Paula, 1999, 1998b, 1996)

A falta de cuidados sanitários fez proliferar a malária, antes restrita a algumas áreas isoladas da região, como Arrozal. A doença espalhou-se e tornou-se uma terrível epidemia, fazendo sucumbir milhares de pessoas nas cercanias da represa, sem alarde. Metade dos 7.000 habitantes da outrora invejável São João Marcos foi contaminada pela peste. Muitas pessoas morreram (770 óbitos registrados em 1910), outras fugiram abandonando casas e terras (Cabral, 2006; Paula, 1998a, 1996).

Daí em diante, o município foi enfraquecendose cada vez mais, num processo de decadência econômica e política. Finalmente, em 1938, o governo estadual decretaria a sua anexação ao município vizinho, Rio Claro, o que, sem dúvida contribuiria ainda mais para a sua destruição definitiva (Cabral, 2006; Paula, 1996).

A Light, na década de 1930, começou a projetar a expansão da represa de Lajes, uma vez que a cidade do Rio de Janeiro continuava crescendo e sua população já ultrapassara 1,5 milhão de habitantes (Szmrecsányi, 1986). A expansão da represa estaria ligada à elevação do nível das águas, o que levaria, inevitavelmente, à extinção de São João Marcos. De um lado, a Light, a grande imprensa e os governos estadual e federal; de outro o povo que queria preservá-la. Quando tudo parecia perdido, os moradores ganharam um apoio inesperado: o departamento cultural do Estado, representado por Rodrigo Mello Franco de Andrade, indicou a cidade como "monumento cultural" e exigiu a sua preservação. A questão repercutiu na imprensa fluminense e, no mesmo ano de 1939, o Serviço de Patrimônio Histórico e Artístico Nacional - SPHAN tombou a cidade. Classificada oficialmente como "raro exemplo intacto de conjunto de arquitetura colonial" (Araújo, 2008; Cabral, 2006; Paula, 1999).

$\mathrm{O}$ governo cedeu à pressão da Light e em 1940 o presidente Getúlio Vargas entregou a cidade, desconsiderando a decisão do SPHAN e as reivindicações da população. Foi o primeiro caso de "destombamento" no Brasil. O decreto-lei no 2.269 autorizou a desapropriação de terrenos, prédios e quaisquer benfeitorias, que viessem a ser inundadas. Promessas foram feitas e decretos assinados com o objetivo de garantir a reconstrução da cidade em outro local - e nada foi cumprido (Araújo, 2008; Cabral, 2006; Paula, 1999).

As demolições começaram numa Quinta-Feira Santa. A população protestou, saindo pelas ruas com cartazes que diziam: "somos 4.600 brasileiros e não queremos desaparecer". De nada adiantou, as turmas de operários com marretas se sucederam, os prédios próximos da represa foram demolidos por barcos rebocadores com cabos de aço e o restante dos quarteirões foi reduzido a pedregulhos pela dinamite. Apenas o cemitério foi respeitado e parcialmente transferido para o alto de um morro. São João Marcos finalmente estava extinta, em ruínas. Era hora de levá-la para o fundo das águas (Araújo, 2008; Cabral, 2006; Paula, 1994). 
À distância, do alto dos morros, ex-moradores, curiosos e funcionários da Light acampados precariamente se acotovelavam para verem sumir a terra que um dia abasteceu toda a Europa de café. Pela segunda vez, São João Marcos seria inundada pelas águas revoltosas e turvas que apagavam os rastros de 200 anos de trabalho, fausto e progresso (Cabral, 2006; Paula, 1994).

Hoje, do que foi São João Marcos em seus tempos áureos, nada resta a não ser histórias, a não ser ruínas. A prefeitura de Rio Claro em parceria com a LIGHT, criou um parque no local das ruinas da antiga cidade, no local da antiga cidade, como forma de resgatar e manter viva a memória daquela que foi uma das cidades mais prósperas do País.

\section{CONSIDERAÇÕES FINAIS}

Embora tenham sido muitos os impactos tanto ambientais quanto socioeconômicos associados à criação do reservatório de Lajes, ela foi de extrema importância para a cidade do Rio de Janeiro, no que diz respeito à sua eletrificação, a qual possibilitou um grande avanço no desenvolvimento tanto para a indústria quanto para os transportes públicos da cidade.

Se por um lado as demolições desnecessárias e a não construção de nova cidade para abrigar a população desabrigada foram um dos fatores determinantes para o fim de São João Marcos, por outro possibilitaram a regeneração de extensas áreas de mata atlântica no entorno do reservatório, o que, associado ao reduzido número de habitações, contribui para a manutenção da qualidade de suas águas que hoje, além de sua utilidade para fins energéticos, ainda abastecem alguns bairros do Rio e algumas cidades da baixada, sendo uma reserva estratégica para o abastecimento público de água da região metropolitana em caso de impedimento de captação de águas do rio Paraíba do Sul.

\section{STATUS DA SUBMISSÃO}

Recebido: 25/11/2009

\section{AUTOR(ES) PARA CORRESPONDÊNCIA}

\section{Eduardo Oliveira Estiliano}

Laboratório de Ecologia de Peixes, Universidade Federal Rural do Rio de Janeiro, Km 47, Antiga Rodovia Rio-SP, CEP 23851-970, Seropédica, RJ, Brasil

e-mail: eoebr@yahoo.com.br

\section{REFERENNCIAS}

Araújo TB. Patrimônio cultural e comentários a respeito do episódio ocorrido na cidade de São João Marcos [monografia]. Santa Cruz: Universidade Estácio de Sá; 2008.

Beiler ACMIJB. Cidades mortas: declínio econômico das cidades do médio Paraíba na província do Rio de Janeiro no ciclo café. Aspectos econômicos, históricos e sociais das cidades de Piraí, São João Marcos e Rio Claro no período de 1860 - 1900 [monografia]. Volta Redonda: Centro Universitário de Volta Redonda UNIFOA; 2001.

Bopp I. Vilas e povoados visitados na viagem de Dom Pedro I. Revista do Instituto Histórico e Geográfico de São Paulo 1973; 70(1):697-706.

Cabral EMG. Rio Piraí: mudanças ambientais e transformações sócio-culturais, curso percurso e transcurso de um corpo d'água [dissertação]. Rio de Janeiro: Pontifícia Universidade Católica; 2006.

Dantas LA. Esboço Biographico do Dr. Joaquim José de Souza Breves: origem das fazendas São Joaquim da Gramma e Santo Antonio da Olaria: subsidios para a historia do municipio de São João Marcos. Rio Claro; 1931. $24 \mathrm{p}$.

Hansen CRSO. Serzedelo Corrêa, a Companhia Brasileira de Energia Elétrica e Eletricidade no Distrito Federal no início do século XX. In: Anais do Simpósio de Pós- Graduação em História Econômica; 2008; p. 1-24.

Kessel C. A vitrine e o espelho: o Rio de Janeiro de Carlos Sampaio. Rio de Janeiro: Secretaria das Culturas, Departamento Geral de Documentação e Informação Cultural, Arquivo Geral da Cidade do Rio de Janeiro; 2001.

Lamarão S. Capital privado, poder público e espaço urbano: a disputa pela implantação dos serviços de energia elétrica na cidade do Rio de Janeiro (1905 1915). Rio de Janeiro; 2002. Revista Estudos Históricos 2002; 29(1):75-96.

Light/Iesa Internacional de Engenharia S/A. Reservatório de Lajes - Estudo de viabilidade para o alteamento do nível d'água. Rio de Janeiro 1991. 1:1-102. Relatório Final SLP. 
Pasin JL. A jornada histórica do príncipe regente Dom Pedro pelo vale do Paraíba em agosto de 1822. Revista do Instituto Histórico e Geográfico de São Paulo 1973;70(1):575-586.

Paula DA. A cidade submersa: o processo de destruição de São João Marcos (1930 - 1945) [dissertação]. Rio de Janeiro: Universidade Federal do Rio de Janeiro, 1994.

Paula DA. A história de uma morte anunciada. Tempos Históricos 1999; 1(1):67-92.

Paula DA. A Light no Brasil: a história como tragédia. Ciência Geográfica 1998a; 10:41-48.

Paula DA. De tesouros submersos. História e Memória 1998b; 2:06-07.
Paula DA. Na contramão da utopia: a memória da destruição de São João Marcos. Revista de História Regional 1996; 1(1):41-56.

Rocha ASS. A sedução da luz: eletrificação e imaginário no Rio de Janeiro da belle èpoque. Revista de História Regional 1997; 2(2):51-80.

Szmrecsányi T. Apontamentos para uma história financeira do grupo Light no Brasil (1899 - 1939). Revista de Economia Política 1986; 6(1):132-135.

Weid EVD. A expansão da Rio de Janeiro Tramway Light and Power ou as origens do "Polvo Canadense" 2008a. [cited 2008 dez. 20]. Available from: www. casaruibarbosa.gov.br.

Weid EVD. O bonde como elemento de expansão urbana do Rio de Janeiro 2008b. [cited 2008 dez. 20]. Available from: www.casaruibarbosa.gov.br. 